\title{
Eine Ohr-Feige im Palmenhaus
}

\author{
Hilke Steinecke
}

\begin{abstract}
The Elephant Ear Fig (Ficus auriculata) has large edible fruits. It is also an ornamental plant. That can be cultivated in pots, too. In the Palmengarten it is displayed in the palm house, where it often sets fruits.
\end{abstract}

\section{Zusammenfassung}

Die Ohrfeige (Ficus auriculata) bildet große essbare Früchte. Gleichzeitig ist sie auch eine beliebte Zierpflanze. Sie kann bei uns als Kübelpflanze gehalten werden. Im Palmengarten gedeiht sie im Palmenhaus, wo sie regelmäßig fruchtet.

\section{Ohr-Feige}

Bei dem Begriff Ohrfeige denken die meisten vermutlich zunächst nicht an einen Feigenbaum, sondern eher an einen fegenden Schlag mit der flachen Hand in das Gesicht. Bei der Ohr-Feige handelt sich um eine Pflanzenart der Gattung Ficus mit ohrförmigen Blättern.

\section{Ein Feigenbaum aus Asien}

Steigt man im Palmenhaus auf der rechten Seite die Treppe auf die Empore mit den Kakadus hoch, fällt im rechten Seitenbeet ein besonderer Feigenbaum auf. Das Exemplar hat keine länglich-eiförmigen Blätter wie viele andere FicusArten. Die relativ großen Blätter sind im Umriss rundlich und erinnern etwas an Ohren von Elefanten, weshalb die Art auch Ohr-Feige oder Elefantenohr-Feige genannt wird. Bisweilen wird diese Art auch noch als Roxburgh-Feige bezeichnet nach ihrem veralteten Synonym Ficus roxburghii. William Roxburgh (1751-1815), dem zu Ehren sie benannt wurde, war ein schottischer Arzt und Botaniker. Er arbeitete u. a. im Auftrag der East India Company, wirkte als Naturforscher in der Regierung von Madras und wurde später Direktor des Botanischen Gartens in Calcutta. Die aktuelle wissenschaftliche Bezeichnung ist Ficus auriculata, wobei der Artbeiname auriculata von dem lateinischen Wort auricula (Ohr) abzuleiten ist.

Abb. 1: Ficus auriculata im Palmenhaus.

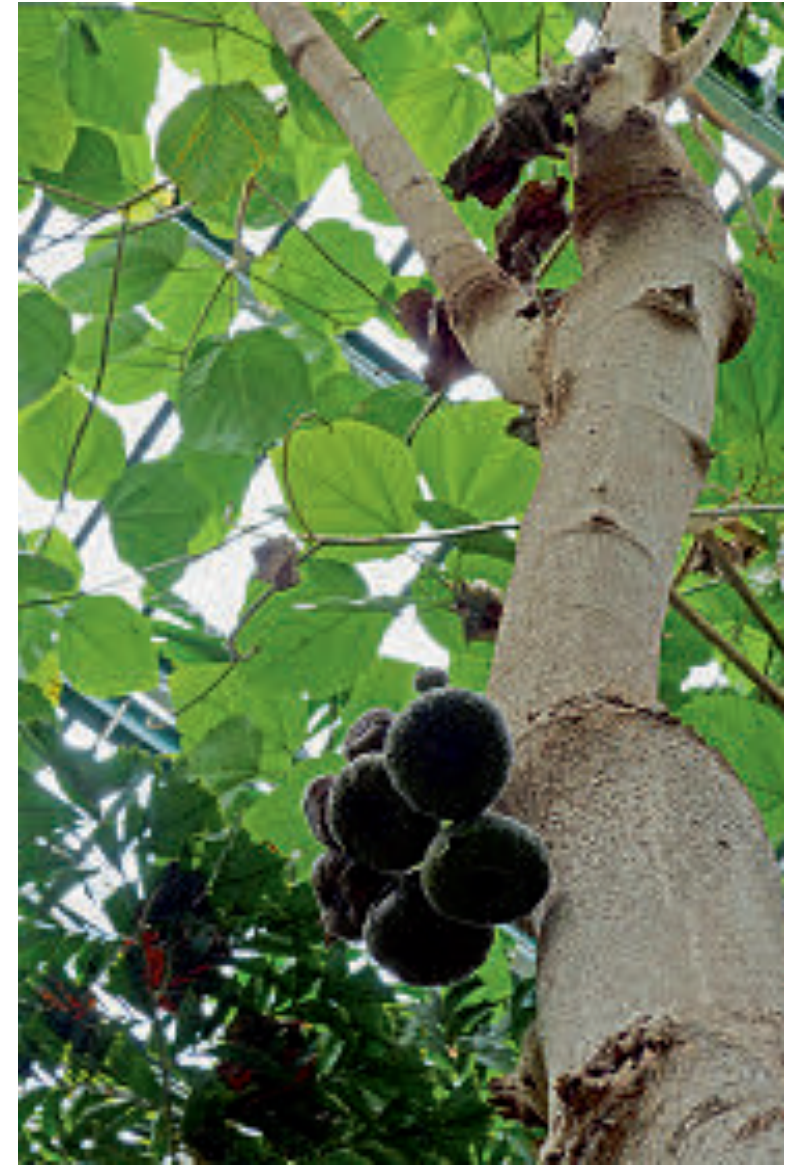

Ficus auriculata ist in Asien heimisch und wird vom Himalaya über Indien, Südchina bis nach Malaisia häufig kultiviert. Auf seine asiatische Verbreitung bezieht sich ein weiterer deutscher Name, nämlich Himalaya-Feigenbaum. Bevorzugt kommt die Ohr-Feige im Regenwald vor, und dort besonders in Tälern oder entlang von Flüssen. Man findet den Baum bis auf 2000 m Höhe. 

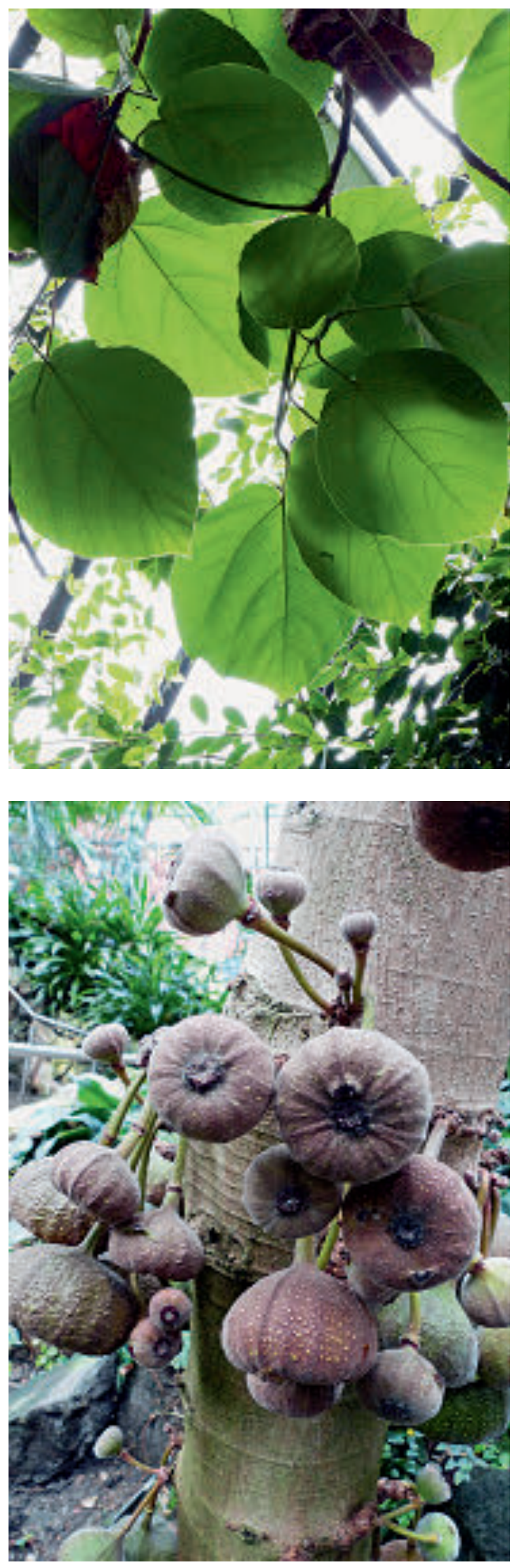

In der Natur wächst Ficus auriculata baumbis strauchförmig und erreicht Höhen um 10 m bei einem Stammdurchmesser von $45 \mathrm{~cm}$. Die Krone kann breit und ausladend werden. Mit bis $40 \mathrm{~cm}$ breiten und bis $50 \mathrm{~cm}$ langen Spreiten sind die Blätter recht groß. Dazu kommt ein gut $20 \mathrm{~cm}$ langer Blattstiel (Walter et al. 1989).

\section{Kauliflorie}

Die Blüten und später die reifen Feigenfrüchte bilden sich am Hauptstamm (Kauliflorie) und seltener an kräftigen Seitenzweigen. Sie befinden sich in Gruppen zu mehreren von der Basis des Stammes bis in die Krone, sodass sie im Palmenhaus vom Weg aus sehr gut betrachtet werden können. Die geschlossenen Blütenstände sind kugelig und enthalten in ihrem Innern viele winzige Blüten. Ähnlich wie auch bei der uns bekannten Essfeige ist der Bestäubungsvorgang sehr kompliziert und hochspezialisiert. Feigengallwespen (Ceratosolen emarginatus) dringen durch eine Pore (Ostiolum) in den Blütenstand ein und fungieren als Bestäuber. Mit ihrem langen Legebohrer legen sie ihre Eier in einen Teil der Blüten, sodass sich in deren Fruchtknoten die Insekten entwickeln können.

\section{Feigenfrüchte}

Was herkömmlich als Feigenfrüchte bezeichnet und gegessen wird, sind Steinfruchtverbände. Die einzelnen kleinen Steinfrüchte spürt man beim Verzehr als kleine Körnchen. Diese für Ficus-Arten typische Scheinfrucht wird auch Syconium genannt.

Abb. 2 (oben): Die großen ohrförmigen Blätter der Ohr-Feige.

Abb. 3 (unten): Die Feigenfrüchte stehen in Büscheln direkt am Stamm.

Abb. 4 (Seite 87 oben links): Feige mit Ostiolum.

Abb. 5 (Seite 87 oben rechts): Eine aufgeschnittene Ohr-Feige erinnert an ein Herz. Beim Anschneiden tritt weißer Milchsaft aus. In der Bucht des Herzes befindet sich das Ostiolum.

Abb. 6 (Seite 87 unten): Schnitt durch eine Feigenfrucht von Ficus carica aus dem Palmengarten. 


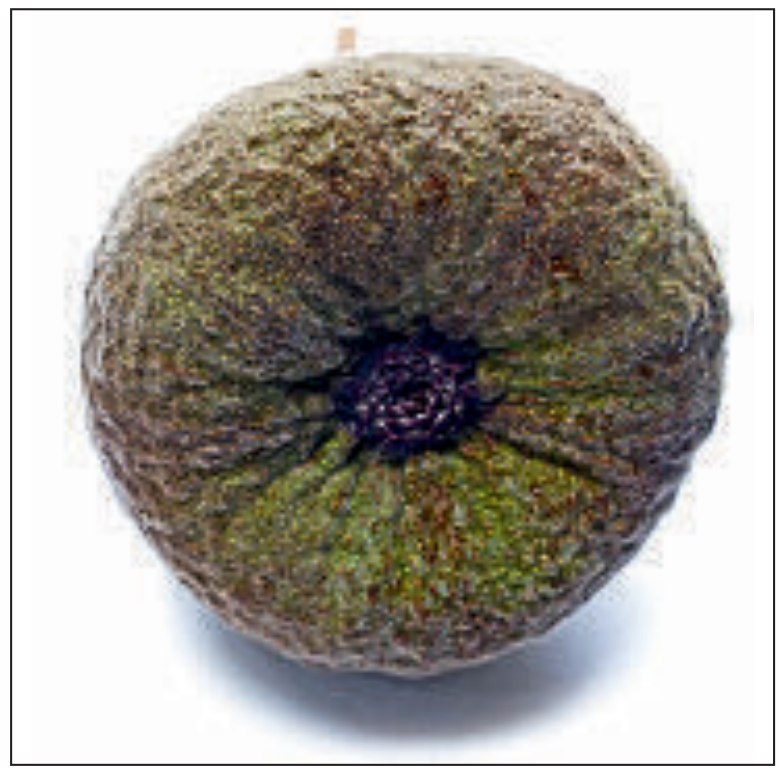

Die Scheinfrüchte von Ficus auriculata werden 4-8 cm breit, sind apfel- bis birnenförmig und auf der dem Stiel gegenüberliegenden Seite abgeflacht. Die älteren Bezeichnungen Ficus macrocarpa und $F$. pomifera beziehen sich auf diese relativ großen, apfelähnlichen Früchte.

Die innen roten Scheinfrüchte enthalten einen recht großen Hohlraum. Eine längs aufgeschnittene Ohr-Feige erinnert an ein rotes Herz. Ohr-Feigen werden frisch und roh oder gekocht gegessen. Sie werden auch zu Curries und Konserven verarbeitet. Der Geschmack gilt als etwas bitter mit einer Note nach Ananas und Erdbeere. Beim Kochen geht der bittere Geschmack verloren.

Ficus auricuata ist nicht nur ein Obstgehölz. Der Baum wird zudem gegen Erosion angepflanzt. Als Zierpflanze lässt sich diese Feige auch im Kübel halten. Rückschnitt verträgt sie gut und sie soll danach umso buschiger austreiben.

\section{Literatur}

Walter, S. M, Alexander, J. C. M., Brady,

A., Brickell, C. D., Cullen, J., Gree, P. S., Heywood, V. H., Matthews, V. A., Robson, N. K. B., Yeo,

P. F. \& Knees, S. G. (Hrsg.) 1989: The European Garden Flora. Volume III, Dicotyledons (Part I). - Cambridge, New York, New Rochelle, Melbourne, Sydney.

\section{Internetseiten}

http://www.smgrowers.com/products/plants/plantdisplay. asp?plant_id=647

http://toptropicals.com/catalog/uid/Ficus_auriculata.htm
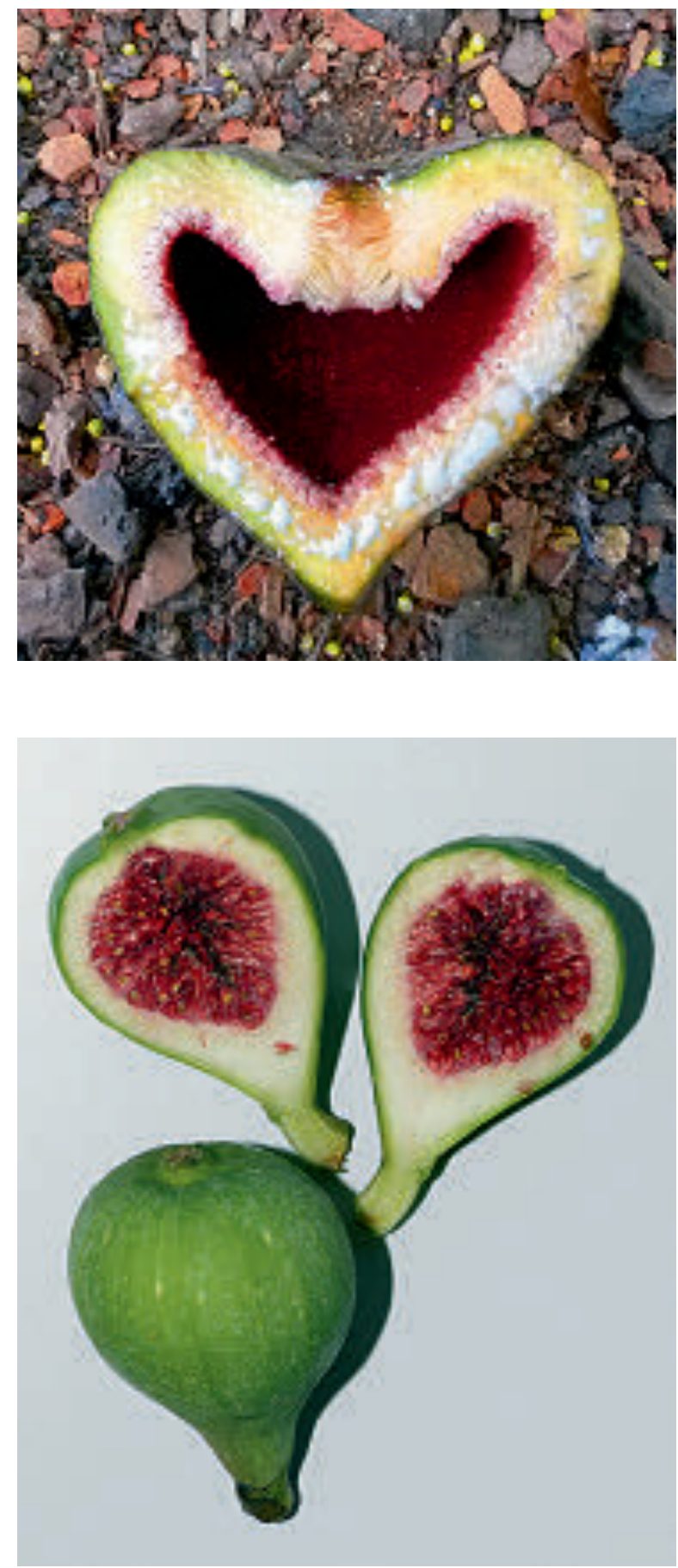